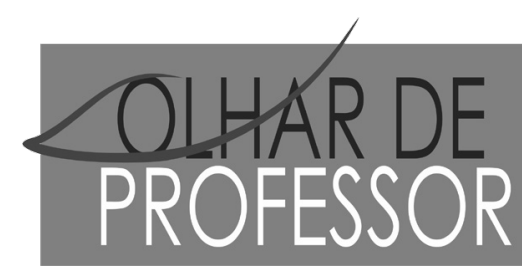

DOI: 10.5212/OLHARPROFR.v.2112.0007

\title{
O ENSINO DE QUÍMICA NO ENSINO FUNDAMENTAL EM UMA ESCOLA WALDORF: POSSIVEIS OLHARES
}

\section{THE CHEMISTRY TEACHING AT ELEMENTARY SCHOOL IN A WALDORF SCHOOL: POSSIBLE VIEWS} LA ENSEÑANZA dE QUÍIIICA EN LA ENSEÑANZA FUNDAMENTAL EN UNA ESCUELA WALDORF:
POSIBLES MIRADAS

\author{
FERNANDA LUIZA FARIA* \\ IVONI FREITAS-REIS
}

\begin{abstract}
Resumo: O presente estudo visou investigar como o ensino da química é estabelecido em uma escola Waldorf no Ensino Fundamental. Para isso, tomamos como ambiente de pesquisa, a escola Paineiras Waldorf, localizada na cidade de Juiz de Fora, Minas Gerais. Os participantes foram dez alunos de uma turma do oitavo ano e a professora responsável por ela. Foi observada a época de química do oitavo ano. As aulas foram gravadas em áudio, e foi construído um diário de campo. Foram analisados os cadernos de anotações dos alunos sobre as aulas, sendo o registro por fotografia. A entrevista semiestruturada foi realizada com os alunos e a professora da turma, sendo gravadas em áudio e posteriormente transcritas. A análise dos dados ocorreu através da Análise de Conteúdo. Os resultados apontaram para um currículo baseado em eixos temáticos, uma abordagem contextualizada e interdisciplinar dos saberes químicos, com valorização da arte e da experimentação.
\end{abstract}

Palavras-chave: Pedagogia diferenciada. Ensino de Química. Ensino Fundamental.

Abstract: The present study aimed to investigate how the teaching of chemistry is established in a Waldorf elementary school. For this, we take as research environment, the Paineiras Waldorf school, located in the city of Juiz de Fora, Minas Gerais. The participants were ten students from an eighth grade class and the teacher responsible for them. The eighth grade chemistry season was observed. The classes were recorded in audio, and a field diary was built. The students' notebooks on the classes were analyzed, being recorded by photograph. The semistructured interview was carried out with the students and the teacher of the class, being recorded in audio and later transcribed. The analysis of the data occurred through Content Analysis. The results pointed to a curriculum based on thematic axes, a contextualized and interdisciplinary approach to chemical knowledge, valuing art and experimentation.

Keywords: Differentiated Pedagogy. Chemistry Teaching. Elementary Education.

Resumen: El presente estudio tiene como objetivo investigar cómo la enseñanza de la química se establece en una escuela Waldorf en la Enseñanza Fundamental. Para ello, tomamos como ambiente de investigación, la escuela Paineiras Waldorf, ubicada en la ciudad de Juiz de Fora, Minas Gerais. Los participantes fueron diez alumnos de una clase de octavo año y la profesora responsable por ella. Se observó la clase de química del octavo año. Las clases se grabaron en audio, y se construyó un diario de campo. Se analizaron los cuadernos de anotaciones de los alumnos sobre las clases, siendo el registro por fotografía. Entrevistas semiestructuradas fueron realizadas con los alumnos y la profesora de la clase, siendo grabadas en audio y posteriormente transcritas. El análisis de los datos ocurrió a través del análisis de contenido. Los resultados evidenciaron un currículo basado en ejes temáticos, un abordaje contextualizado e interdisciplinario de los saberes químicos, con valorización del arte y de la experimentación.

Palabras claves: Pedagogía diferenciada. Enseñanza de Química. Enseñanza Fundamental.

\footnotetext{
* Doutora em Química, área de concentração em Educação Química, pela Universidade Federal de Juiz de Fora. Professora na Universidade Federal de Santa Catarina, campus Blumenau. Fernanda.faria@ufsc.br.

${ }^{* *}$ Doutora em História da Ciência pela Pontifícia Universidade Católica de São Paulo. Professora na Universidade Federal de Juiz de Fora. Ivoni.reis@ufjf.edu.br.
} 


\section{INTRODUÇ̃̃̃O}

Diferentes perspectivas educacionais balizam os projetos político-pedagógicos de algumas escolas em torno do mundo. Trata-se de instituições de ensino que buscam uma diferenciação pedagógica, uma proposta de ensino que visa contribuir significativamente para a formação de cidadãos conscientemente críticos e ativos em sociedade. A proposta de diferenciação pedagógica está fundamentada na compreensão de que todos têm o direito de aprendizagem, sendo o aprender, algo complexo que precisa considerar as diferentes necessidades de cada aluno. (GRIMES; STEVENS, 2009; SANTOS, 2009; MORGAN, 2014).

As diferenças de aprendizagem não estão apenas no tempo que o indivíduo leva para dominar determinado conhecimento, mas sobretudo nas diversas maneiras de pensar e relacionar o que já sabemos com o que aprendemos de novo. (SANTOS, 2009). A pedagogia diferenciada traz uma abordagem singular, com a preocupação de trabalhar a educação de forma mais centrada no aluno e em seu percurso. Diferenciar o ensino é um processo que desafia os nossos conhecimentos, nossas vontades instáveis e ainda nossas divergências. (PERRENOUD, 2000).

Alicerçados no âmbito da pedagogia diferenciada, trazemos, como cenário de investigação, a proposta pedagógica constituída nas escolas Waldorf. Essa pedagogia de ensino busca a formação do ser humano como um todo, desenvolvendo diferentes aspectos de forma harmoniosa como a inteligência, a vontade, as ideais sociais, os conhecimentos, a moral, entre outros. (BOGARIM, 2012). Ela busca formar um indivíduo que esteja preparado para conhecer o mundo que o cerca e atuar e viver dentro dele. (LANZ, 2003). Essa escola defende ainda uma mesma formação humana para todos. Isto posto, nos adentramos neste artigo para um contexto mais especifico, o ensino de química estabelecido nestas escolas, desde logo, no ensino fundamental.

A realidade educacional brasileira aponta para um ensino de química, no ensino médio, fragmentado e descontextualizado, que pouco contribui para a formação de um aluno crítico e atuante na sociedade. $\mathrm{O}$ que se inicia no ensino fundamental, quando o ensino de ciências é trabalhado nos primeiros anos apenas sob o viés biológico, deixando unicamente o último ano para ser trabalhado os saberes da química e da física. Nesta proposta, na maioria das vezes, há meramente uma antecipação do conteúdo químico do ensino médio já no ensino fundamental. Corroboramos com as discussões de alguns pesquisadores. (REIS, 2012; AUTORES APEC, 2003; LIMA; SILVA, 2007), que defendem a abordagem do conhecimento químico iniciando-se em anos anteriores do ensino fundamental, de forma que os fenômenos científicos estudados nesse período possam ser compreendidos pelos alunos sob o viés biológico, químico e físico que constituem as ciências da natureza.

Documentos oficiais como os Parâmetros Curriculares Nacionais (Brasil, 1998), a Base Nacional Comum Curricular (Brasil, 2016), e diversas pesquisas no campo da Educação Química. (REIS, 2012; SILVA, 2014; LIMA; SILVA, 2007; AUTORES APEC, 2003; MILARÉ; ALVES FILHO, 2010; LIMA; AGUIAR JUNIOR, 1999), têm enfatizado a relevância da contextualização e da interdisciplinaridade no ensino da química, das relações entre ciência e tecnologia na sociedade frente a aspectos políticos, econômicos e culturais, da discussão da natureza do conhecimento cientifico e a contribuição para uma visão da ciência como construção humana, sempre ambicionando a formação do aluno crítico, atuante e transformador da sua realidade.

Ao que se refere à pesquisa em educação, alguns trabalhos sobre a Pedagogia Waldorf têm sido realizados discutindo sobre a pedagogia da escola e seu espaço escolar. (PILONI, 2008; BACHEGA, 2009; BOGARIM, 2012; SENA, 2013; SANTOS, 2010, 2015). Contudo, têm sido poucas as publicações a respeito do ensino de ciências na Escola Waldorf, o que nos levou a investigar mais a respeito desse ensino, especificamente, para o contexto da química. Assim, nos propomos, neste trabalho, a investigar como o ensino da química é estabelecido nas escolas Waldorf no Ensino Fundamental e de que maneira os seus objetivos educacionais, que tangenciam os objetivos da educação brasileira, são alcançados em sua proposta para o ensino da química, já em anos anteriores do ensino fundamental. 


\section{A PEDAGOGIA WALDORF: BASE FILOSÓFICA E PRECEITOS}

A Pedagogia Waldorf começou a se estabelecer em 1919, em Stuttgart, na Alemanha, quando Emil Molt, diretor de uma fábrica de produção de cigarros, convidou Rudolf Steiner ${ }^{1}$ (1861-1925) para formar uma escola que abordasse a perspectiva antroposófica e que pudesse atender aos filhos dos operários e dos funcionários de sua fábrica. A fábrica se chamava Waldorf-Astoria e foi daí que surgiu o nome para esta pedagogia. Posteriormente à criação da primeira escola Waldorf, a experiência da escola passou a ser divulgada por Steiner em várias conferências, o que contribuiu para a expansão dessa pedagogia no mundo.

O sistema pedagógico está alicerçado na Antroposofia, também criada por Steiner. Essa filosofia tem como significado o conhecimento humano e, para seu fundador, ela nasceu de uma "profunda necessidade cultural", pois quando se trata do "pensar científico-natural, precisamos justamente de uma nova compreensão do ser humano, pois é assim que conseguiremos também uma compreensão da essência do mundo.” (STEINER, 2013, p. 19).

As escolas Waldorf são regidas por três princípios básicos: a liberdade quanto às metas de educação; a liberdade quanto ao método pedagógico; e a liberdade quanto ao currículo; na busca por uma escola autônoma. Elas têm se expandido cada vez mais ao redor do mundo, em 2010 havia aproximadamente 650 escolas na Europa, no mundo todo havia mil escolas distribuídas em 61 países e mais de 1600 Jardins de Infância. (ALVES, 2011). No Brasil, em 2016, segundo a Federação das Escolas Waldorf no Brasil (FEWB), havia 33 escolas filiadas que adotavam apenas o Ensino Infantil, 20 delas possuíam o Ensino Infantil e Fundamental e 10 que apresentavam além do Ensino Infantil e Fundamental, também o Ensino Médio. Dessas 10 escolas, 8 se encontram no estado de São Paulo, 1 no estado de Minas Gerais e 1 no estado de Santa Catarina. As Escolas Waldorf são reconhecidas pelo MEC e pela UNESCO e trazem uma perspectiva educacional diferenciada das escolas tradicionais, o que reflete em seu currículo, na sala de aula, na formação do professor, nas estratégias de ensino e de avaliação adotadas, dentre outros.

No contexto do Ensino Fundamental, a escola Waldorf possui os professores de classe, os professores especialistas ou de área e os professores auxiliares. Os professores de classe são aqueles que lecionam diversas disciplinas e que estão presentes em maior tempo em sala de aula com os alunos. Os professores especialistas ou de área, são aqueles responsáveis pelas disciplinas de línguas como inglês e alemão, os trabalhos manuais, jardinagem, mercearia, educação física, música, euritmiaª Cabe ressaltar que os professores responsáveis por essas disciplinas, possuem graduação, especialização, cursos técnicos, ou ainda experiência na sua área de ensino. Por fim, os professores auxiliares ou substitutos, ou estagiários, são aqueles que ajudam os demais professores quando necessário como, por exemplo, auxílio na preparação e materiais para as aulas, acompanhamento de turmas com muitos alunos ou com alunos com deficiências, dentre outras funções. (SANTOS, 2015).

O professor de classe, na maioria das vezes, acompanha o aluno da primeira até a oitava série. Ele leciona as matérias tradicionais, na qual Lanz (2003) declara que o professor não precisa ter uma formação específica, e cita como exemplos: linguagem, aritmética, geografia, história, física, química e caso sinta à vontade e afim, pode ainda se tornar responsável por disciplinas como os trabalhos manuais e a educação física. Quando os alunos chegam à nona série, esse formato é modificado e as matérias passam a ser ministradas por professores especializados nas diferentes áreas. Há ainda um tutor para cada classe que atua como um elo entre os alunos e a escola e inclusive com os pais. Esse tutor na maioria das vezes é escolhido pelos próprios alunos.

Na Pedagogia Waldorf é estabelecido o ensino por épocas, caraterístico dessas escolas. Essa organização foi pensada por Steiner com a finalidade de que as crianças não tivessem sua atenção dispersada o tempo todo.No ensino por épocas, a primeira aula do dia retrata os conhecimentos de uma mesma matéria por três ou quatro semanas, ao invés de as diluir em duas ou três aulas por semana, durante o ano todo. Posteriormente, as matérias artísticas, artesanais, educação física, música, língua estrangeira, entre

\footnotetext{
${ }^{1}$ Rudolf Steiner nasceu em 27 de fevereiro de 1861, em DonjiKraljevec, na Croácia, formou-se na Escola Politécnica de Viena em engenharia e concluiu em 1890 o doutorado em Filosofia na Universidade Rostock, na Alemanha. Em 1910 se dedicou a criar a Antroposofia, faleceu em 1925 na Suíça. Rudolf Steiner foi um filósofo, cientista e artista.

${ }^{2}$ A euritmia é uma nova forma de dança que vem sendo desenvolvida desde 1912. Ela baseia-se no conhecimento do ser humano e do mundo como apresentado na Ciência Espiritual de Rudolf Steiner, a Antroposofia.
} 
outras são realizadas no dia. Após o fim de uma época, tem-se o começo da época de outra disciplina. Ao longo de todo ano, todas as matérias do ano são dadas. Steiner aponta que, durante a época, o ensino deve ser ministrado "de acordo com a necessidade, se assim posso dizer, e não de um modo que tenha algo de obrigatório, e sim num tom sério e leve.” (STEINER, 2013, p. 162).

Especificamente sobre o ensino de ciências, na Escola Waldorf, as ciências da natureza englobam os saberes da zoologia, botânica, mineralogia, química, física e astronomia. Esses conhecimentos são compreendidos por esta pedagogia como aqueles que possibilitam levar o mundo para o interior da classe e abrir os olhos dos alunos para ele. Nesta pedagogia, a idade certa para iniciar esses saberes com os alunos é a partir dos nove, dez anos de idade. A zoologia é dada já no quarto ano do Ensino Fundamental, a botânica inicia no quinto ano, a física no sexto e a química no sétimo.

Quando o aluno atinge em torno dos onze anos, temos um destaque da pedagogia Waldorf para a abordagem de disciplinas como a química e a física, todavia, numa perspectiva em que os fenômenos sejam enaltecidos. Busca-se, de alguma maneira, encontrar o ‘esqueleto’ das várias ciências. Nesta proposta de ensino, tem-se uma visão de que seria errôneo trabalhar, antes dos doze anos, esses saberes a partir de raciocínios focados em definições e em leis abstratas. Ao discutir a química sob o olhar da pedagogia Waldorf, Lanz (2003, p. 134) destaca

Com a química atinge-se como um submundo; não se fala em objetos, mas em substâncias. Mas, também aí, o que está no centro é o relacionamento com o homem: o uso e a produção de certas substâncias da vida humana de todos os dias, processos químicos da vida cotidiana ou ligados ao próprio corpo.

\section{METODOLOGIA}

O presente estudo tem caráter qualitativo e se propõe a estabelecer um processo descritivo, no qual a fonte de dados é o ambiente natural e o investigador é o instrumento principal de pesquisa. (BOGDAN; BIKLEN, 1994).

Nosso ambiente de pesquisa foi a Paineira Escola Waldorf, localizada na cidade de Juiz de Fora, no estado de Minas Gerais. Esta instituição teve origem em 1985 e está associada à Federação das Escolas Waldorf do Brasil. Atualmente essa escola conta com duas turmas de Maternal, quatro turmas de Ensino Infantil e nove turmas do Ensino Fundamental, sendo uma turma para cada ano. Em 2011, a primeira turma concluiu o Ensino Fundamental. Trata-se de uma escola privada, que, no entanto, não apresenta fins lucrativos. A escola atende alunos em sua maioria de classe média-alta, tendo alguns alunos de classe média que ganham bolsa de estudos parcial ou total.

A Paineira Escola Waldorf é mantida pela Associação Pedagógica Parsifal, que tem como propósito fundamental a autogestão. Essa associação é a entidade da escola que possui "a personalidade e a responsabilidade administrativa e jurídica, sujeito de direito para as autoridades." ${ }^{3}$ Hoje ela apresenta 60 sócios, os quais englobam professores, pais e amigos da escola. A administração da escola fica a cargo dos próprios professores.

A fim de investigar o ensino de química estabelecido na Paineira Escola Waldorf, nos propusemos a observar uma turma do Ensino Fundamental da escola, que já estudasse os saberes da química. Ao entrar em contato com a instituição, a seleção da turma a ser investigada se deu a partir da aceitação voluntária de uma das docentes da escola. Diante disso, os sujeitos desta pesquisa foram alunos da turma de oitavo ano da instituição e a professora responsável. No período em que a pesquisa foi realizada, a professora era responsável pela abordagem dos saberes da química, física, antropologia, biologia, geografia, história, português e matemática, apenas as disciplinas artísticas e de língua estrangeira eram responsabilidade de outros docentes especialistas nas áreas. A professora tem formação em Agronomia e Pedagogia, atuando desde a implantação da escola, sendo uma das fundadoras da instituição. Além disso, atua em uma escola tradicional, em turmas de alfabetização. Nesta pesquisa ela receberá o nome fictício de Helena, a fim de preservar o anonimato da docente.

\footnotetext{
${ }^{3}$ http://paineiraescolawaldorf.blogspot.pt/. Acesso em setembro de 2017.
} 
Quanto aos alunos, dos 15 que compunham a turma do oitavo ano investigada, 10 aceitaram participar de forma mais presente na pesquisa. A seleção destes alunos ocorreu de forma voluntária, ou seja, aqueles que se sentiram à vontade para participar das entrevistas e que tiveram autorização dos seus responsáveis. Os alunos receberam nomes fictícios, a fim de preservar o anonimato, são eles: Laís, André, Rafael, Isabela, Arthur, Henrique, Miguel, Beatriz, Gabriel e Elisa. Em geral, os alunos são de classe média alta e, no período investigado, tinham em torno de 12 a 13 anos. Estes sujeitos eram alunos participativos, curiosos, criativos, com sensibilidade artística e grande respeito pela professora, por seus colegas e pela pedagogia da escola. Dos 10 alunos entrevistados, Elisa e Arthur tinham recentemente vindo de escola pública que seguia um ensino mais tradicional, os demais já estudavam há alguns anos na Paineiras Escola Waldorf. Além disso, cabe ressaltar que todos os alunos investigados tinham iniciado o estudo da química já no $7^{\circ}$ ano.

O processo de investigação na Paineiras Escola Waldorf se iniciou com a observação do espaço escolar como um todo, sua organização e funcionamento, e da época completa de química da única turma de oitavo ano da escola. A época investigada compreendeu 18 aulas, com duração de duas horas cada aula. As aulas de química observadas eram ministradas, de segunda a sexta, durante 18 dias sequencias, nos dois primeiros horários da manhã, posteriormente eram lecionadas disciplinas de língua estrangeira e/ou disciplinas artísticas. Diante disso, durante as três semanas e meia de investigação na escola, nos primeiros dois horários a pesquisadora observava as aulas de química e nos demais horários observava o funcionamento e organização da escola como um todo.

A observação da época ocorreu sem a participação da pesquisadora, porém, os alunos foram informados sobre o porquê da sua presença no espaço e do objetivo geral da pesquisa. Para registro dos dados, todas as aulas foram gravadas em áudio e posteriormente analisadas. Além disso, a pesquisadora realizou registros da observação em um diário de campo, o qual também se constituiu de uma fonte de dados desta pesquisa.

Neste contexto ainda foram feitos registros dos cadernos de química produzidos pelos alunos entrevistados durante a época investigada. Esse processo se deu a partir de fotografias. A escolha pela análise dos cadernos foi devida ao fato desse material ser a fonte de estudo dos alunos, no qual esses sujeitos colocavam todos os registros das aulas de química, sendo, portanto, uma fonte rica de dados sobre o ensino da química e a aprendizagem do aluno.

Ao fim da época de química, a pesquisadora realizou entrevista com os alunos voluntários. A mesma ocorreu de forma individual, a partir do roteiro de entrevista já elaborado previamente, no qual investigamos a compreensão do aluno acerca das ciências e em específico da química; a relação da química com outras disciplinas; a utilidade da Química para o cotidiano do aluno; a presença dessa ciência na sociedade; e aspectos que esses sujeitos julgam positivos e negativos sobre o ensino de química na escola Waldorf. Apesar de se ter um roteiro já determinado, quando necessário, a pesquisadora realizava outros questionamentos que auxiliassem a esclarecer as questões discutidas no roteiro. Todas as entrevistas foram gravadas em áudio e posteriormente transcritas para análise.

Ulteriormente, foi entrevistada a professora Helena, responsável pelos saberes da química e de outras disciplinas da turma de oitavo ano investigada. A entrevista seguiu um roteiro pré-estabelecido, no qual buscamos conhecer mais sobre diferentes aspectos do ensino de química em uma Escola Waldorf, como por exemplo, o processo de avaliação; o papel do professor de química na aprendizagem dos alunos; as estratégias de ensino adotadas; o ensino de química abordado e sua relação com outras disciplinas e sua contribuição para uma visão mais integradora das ciências; a contribuição do ensino de química nesta escola para a formação do aluno como pessoa. A entrevista também foi gravada em áudio e em seguida, transcrita e analisada.

Os resultados foram tratados a partir da Análise de Conteúdo. (BARDIN, 2011). Uma metodologia de análise que investiga a palavra e o que está por trás dela. Na presente pesquisa, foram utilizadas categorias construídas a posterior, que emergiram dos resultados das observações e das entrevistas com alunos e a professora. O contexto da pesquisa foi representado ao considerarmos como condições de produção de mensagem: o ambiente da pesquisa investigado, a pedagogia que constitui cada escola, dentre outros aspectos. Também foi considerado o perfil do professor, considerando qual o tipo de formação, anos de exercício docente e se leciona em mais de uma instituição. Para concluir, ponderamos o perfil de alunos participantes da pesquisa, observando características e comportamento dos mesmos. 


\section{ANÁLISE E DISCUSSÃO DOS RESULTADOS}

A discussão dos resultados está estruturada em categorias definidas posteriormente à leitura e interpretação do corpus de análise. São elas: (1) Currículo; (2) Experimentação; (3) Relação da Química com outras disciplinas e (4) Avaliação.

\section{CURRÍCULO}

Os conteúdos presentes no currículo provem de uma união entre as propostas de Steiner e as experiências obtidas ao longo dos anos nas Escolas Waldorf e ainda, das exigências curriculares de cada país. Desta forma, o currículo dessa instituição se adequa às leis de cada país, entretanto não se limita apenas a introdução desses conhecimentos, vai além, praticando, conforme já mencionamos, atividades artísticas e corporais. A arte é um aspecto essencial no currículo dessa pedagogia, sendo uma "mediadora do processo de ensino-aprendizagem”, de forma que além das disciplinas artísticas, a prática de ensino adotada para o estudo de qualquer conhecimento, envolve a habilidade artística do professor e do aluno. (SENA, 2013). O que foi possível notar durante a observação dos cadernos dos alunos, os quais são cheios de desenhos coloridos feitos por eles próprios, representando as atividades realizadas durante a época. Como poderá ser visto nas imagens mais à frente na categoria experimentação. A seguir tem as capas dos cadernos de dois alunos.

Figura 1 - Capa do caderno de dois alunos da escola Waldorf analisada

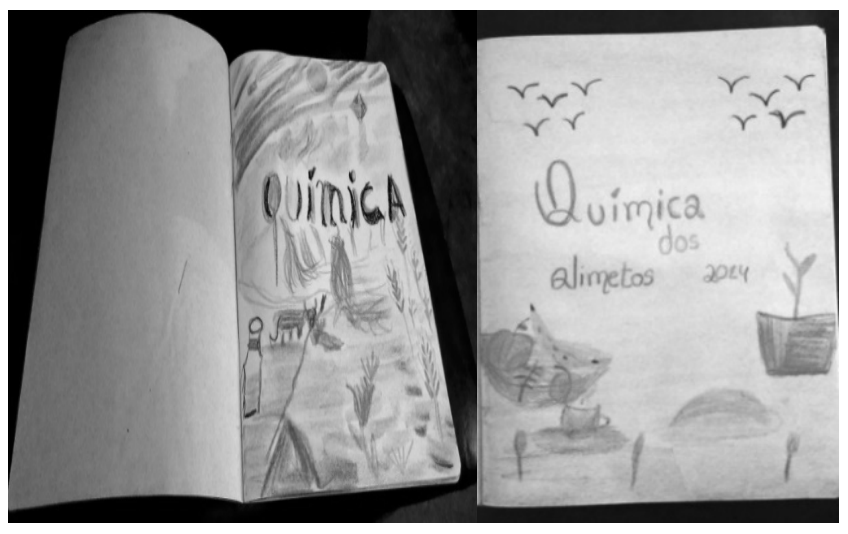

Fonte: Dados da Pesquisa.

A relevância da arte para a educação tem sido assentida na Lei de Diretrizes e Bases da Educação Nacional - Lei 9394/96 (BRASIL, 1996) e nos PCN (BRASIL, 1998) já há algum tempo. A atual BNCC vem reforçar essa percepção, reconhecendo a arte como um conhecimento essencial para a formação plena do cidadão. Como destaca em seu documento, a arte constitui "um universo de experiências, de conceitos e de práticas singulares que engendram arranjos, sentidos e acontecimentos, contribuindo para a interação crítica do/a estudante com a complexidade do mundo.” (BRASIL, 2016, p. 112).

A partir da observação da época de química, foi possível conhecer mais sobre o currículo de química do oitavo ano da escola Paineira Waldorf. Ele está estruturado em um assunto central, os Alimentos, e converge em três eixos temáticos: os Carboidratos; as Proteínas; e as Gorduras, no eixo Carboidratos há uma ênfase no tema Açúcares. Dentro destes tópicos, há ainda um desmembramento em outros, como destaca Sena (2013) ao discutir sobre os conteúdos de ensino sugeridos recentemente ao ensino de ciências Waldorf: "do grão até a farinha; cereais; amido; glúten; proteína; açúcar; fermentação; gorduras e óleos; sabão; celulose; curtume (couro); fabricação de queijo.” (SENA, 2013, p. 105). Durante a observação foi possível perceber que apenas os três últimos tópicos não foram trabalhados na época de química investigada.

Durante a entrevista, a professora Helena foi questionada acerca da maneira em que planejava suas aulas e neste momento, ela trouxe detalhes sobre a abordagem do saber químico no sétimo, oitavo e nono 
ano, como a aula acontece e quais atividades são realizadas. Como neste trabalho foi observado apenas a época de química do oitavo ano, as informações trazidas na entrevista tornam-se de grande interesse para este estudo, enriquecendo as discussões em torno de como se estabelece o ensino de química na Pedagogia Waldorf. Esses apontamentos podem ser evidenciados na fala a seguir da professora. No primeiro trecho ela discorre sobre a química no sétimo ano e no segundo detalha sobre a química no nono ano.

Então eles vivem isso com muita simplicidade, com muita vivência. O sétimo ano tem essa linha, você começa com a queima, a gente queima proteína, matéria vegetal, matéria animal e eles vão percebendo que tem diferença, depois a gente entra no calcário, tanto que a viagem do sétimo ano é em grutas calcárias. Ai a gente entra de leve nessa liberação de gás carbônico, sem formulação nenhuma e depois a gente entra no ácido e na base partindo mesmo da cal. Então o fio do sétimo ano é isso, e cai 'como uma luva'.

No nono ano os açúcares voltam, aí através da fermentação a gente vai fazendo o fio condutor, fermentação e destilação. Então eles veem que aquela planta que eles começaram a trabalhar no quinto ano em botânica gerou o açúcar, que depois pode chegar no álcool. E a gente tem um destilador lá e é muito interessante. A gente põe para destilar o suco de uva, eles sentem aquele cheiro, vê aquele gás saindo, de novo a gente coleta o gás que sai e chega à conclusão que é o gás carbônico. E aí eles veem que esse gás carbônico está em várias situações e depois a gente vai problematizar esse gás na atualidade, mais pra frente.

O currículo Waldorf, de forma geral, se apoia no desenvolvimento do homem e das artes. (SANTOS, 2010). Para Sena (2013), um risco que se corre é a visão do currículo Waldorf de forma prescritiva e normativa por professores dessa pedagogia. No entanto, esse mesmo autor destaca que para Richter (2002), apesar de seguirem as bases do currículo de Steiner, há uma flexibilidade por parte dos docentes em realizar adaptações necessárias. Isso porque a realidade escolar possui diferentes condições como a individualidade do professor e seu comportamento perante a classe, a personalidade de cada estudante, o momento histórico que se constitui e a própria localização geográfica em que se encontra, bem como as questões de leis que regram o ensino de cada escola. (SENA, 2013).

De forma geral, o currículo Waldorf de química é bem diferenciado do currículo tradicional brasileiro utilizado na realidade das escolas; onde há um acúmulo de conteúdo a ser trabalhado com o aluno em apenas um semestre no nono ano. O currículo Waldorf se estrutura em eixos temáticos que se inter-relacionam, aproximam da vivência do estudante e têm relevância para a formação desses sujeitos.

\section{ABORDAGEM DO CONHECIMENTO QUIIMICO}

A partir da observação da época de química, notamos que as aulas seguem uma estrutura bem definida. Inicialmente os alunos vivenciam práticas experimentais, sendo instigados a observar o fenômeno e descrevê-lo. Porém, a reflexão ocorre após o fim da aula, já em casa, depois de um descanso ${ }^{4}$ quando os conceitos aprendidos na aula anterior são colocados no papel. No dia seguinte, na sala de aula, as anotações feitas pelos alunos são retomadas e debatidas junto ao professor e a classe.

A química apresentada no oitavo ano da Paineiras Escola Waldorf se deu a partir de temas relacionados com a vivência do aluno, como já discutido na categoria de Currículo. Todavia, durante a observação da época, constatamos uma abordagem com a ausência de símbolos, fórmulas e equações, sob uma perspectiva apenas concreta e macroscópica. A professora Helena destaca em entrevista que a química é trabalhada na escola Waldorf como uma ciência de transformações e retrata que:

Não é uma química como a gente, eu aprendi na escola, com cadeias, com estruturas. Mas ele vai vivenciando que a química permeia praticamente tudo que está ao nosso redor. Então eles se encantam, eles amam participar daquilo, esperam por uma explosão o tempo todo (risos). A química mesmo chega depois a partir do nono, décimo ano mesmo. [...] Eu acho fundamental eles passarem por essa fase amena pela química, se é que eu posso chamar de amena, porque depois ela se torna alguma coisa mais cognitiva, mais intelectual.

\footnotetext{
${ }^{4}$ Essa reflexão que deve acontecer "depois de um descanso" está implicitamente arraigada a Pedagogia Waldorf, que acredita que o conhecimento necessita "sedimentar" para ser realmente compreendido e maturado.
} 
Ainda sobre os preceitos da pedagogia Waldorf, no contexto específico dos saberes químicos e físicos, Steiner (2013) destaca que estes devem ser trabalhados pelo educador com cautela e de forma bem atrativa. As aulas referentes a esses conhecimentos devem ter encanto, humor e não serem maçante. De fato, esses apontamentos trazidos por Steiner são observados na época de química investigada nesta pesquisa. Um ponto oportuno de ser enfatizado aqui é esse último aspecto destacado por Steiner, afinal, a listagem excessiva de conteúdo de química e a grande memorização dos mesmos já na primeira abordagem da química, pelo aluno, é uma característica que tem predominado nas aulas de química e física nas escolas brasileiras tradicionais e que fazem os alunos não verem sentido em estuda-la e ainda, não terem interesse ou gosto por elas.

\section{EXPERIMENTAÇÃO}

Durante a observação da época, foi possível notar a grande ênfase dada pela escola à experimentação. Em quase todas as aulas de química observadas houve a realização de um experimento, o qual variava em seu formato. Algumas vezes o experimenta era demonstrativo, outros em duplas ou ainda em grupos. Os experimentos realizados eram de baixo custo, podendo ser utilizado pelos professores em qualquer escola. As práticas aconteciam em sala de aula, pois a escola não apresentava laboratório.

Durante a época do oitavo ano foram realizadas práticas como: produção de pão, produção de sabão, teste da presença de iodo em diferentes alimentos, solubilização de sal e açúcar em água a diferentes concentrações e temperaturas, teste da presença de açúcar em sucos de diferentes frutas, separação do glúten presente na farinha de trigo, queima de alguns alimentos, desidratação do açúcar a partir do ácido sulfúrico, dentre outros. Todos as atividades eram realizadas com um grande enfoque na observação e uso dos sentidos, o que reflete nas anotações e desenhos dos alunos em seus cadernos. Como pode ser visto nas imagens e falas dos alunos a seguir:

A professora nos deu diversos alimentos como manga, limão, mexerica, inhame, batata baroa, cenoura, alface, agrião, pão integral e amido, e também nos deu um pouco de solução de iodo. Nós o pingamos em todos os alimentos. A batata e o inhame reagiram ao iodo e ficaram roxo claro, o pão e o amido reagiram e ficaram roxo escuro. As frutas cítricas e as folhas não causaram nenhuma reação. A cenoura e a manga pouco escureceram. Conclusão, tudo que tem amido ao reagir com a solução de iodo pega coloração roxa. (Aluno).

Figura 2 - Representação do aluno sobre a prática de teste de iodo em alimentos

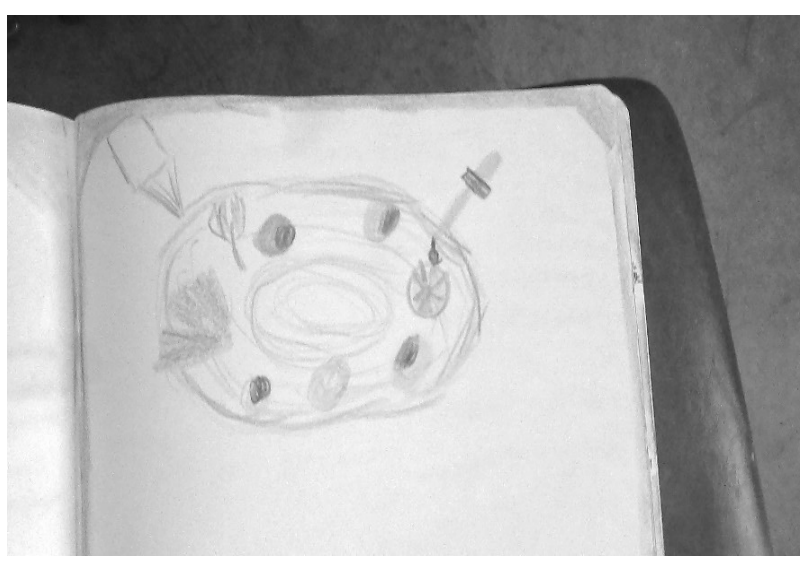

Fonte: Dados da pesquisa.

O óleo não se mistura. (Aluno).

O óleo não é hidrossolúvel. (Aluno).

O óleo é menos denso que a água. (Aluno). 
Figura 3 - Imagem produzida em um relatório, por um aluno da escola Waldorf pesquisada, sobre a mistura de óleo e água

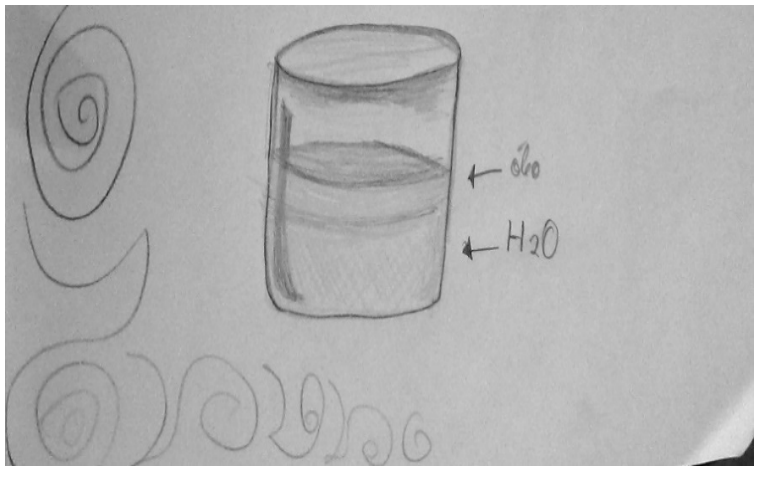

Fonte: Dados da pesquisa.

Hoje abrimos uma padaria na aula, fizemos duas levas de pão para arrecadar dinheiro para o teatro. Observamos que ao cozinhar alguma coisa, o alimento sofre várias reações químicas, como ao colocar o fermento e amassar o pão, o deixamos parado e depois de duas horas, o pão havia crescido. (Aluno).

Figura 4 - Representação do aluno sobre a prática de produção de pão

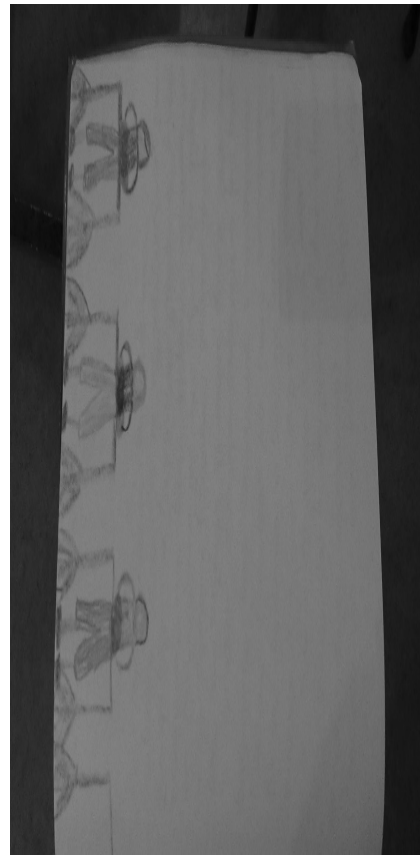

Fonte: Dados da pesquisa.

Figura 5 - Representação do aluno da prática de queima do glúten

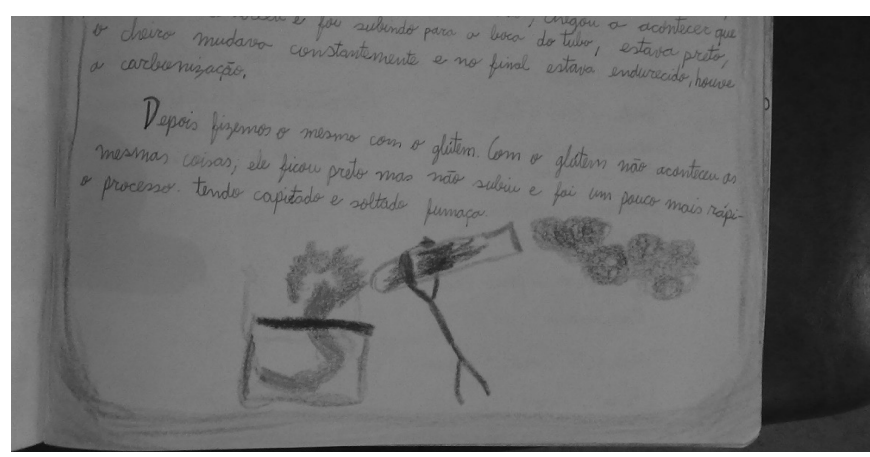

Fonte: Dados da pesquisa. 
O destaque dado para a valorização dos sentidos durante as experiências, reflete inclusive nas falas dos alunos. Questionados sobre o que acontece quando ocorre uma reação química, a maioria deles citou aspectos que caracterizam um fenômeno químico como mudança de cor, aparecimento de bolhas, mudança de temperatura, dentre outros. Como pode ser visto nas falas dos alunos, a seguir:

A coisa tipo muda, às vezes expande ou diminui, muda de cor, fica quente. (Laís).

Algum produto químico entrou em contato com alguma coisa e mudou de cor, ou deu aquelas bolhinhas. (Isabela).

Deve borbulhar, explodir, sair fumaça. (Beatriz).

Esta ênfase na observação do fenômeno, na percepção a partir dos sentidos e na vivência, são características atribuídas pelas ideias de Steiner, que teve parte de suas concepções baseadas nos estudos científicos do alemão Johan Wolfgang Von Goethe (1749-1832). A visão científica goethiana teoriza a prática pedagógica adotada nas escolas Waldorf no ensino de ciências. Isso porque, o método científico de Goethe apresenta etapas bem estabelecidas, como o passo 1, no qual, como aponta Ghelman (2006), trata-se da percepção sensorial exata, na qual o pesquisador deve observar o fenômeno em todos os seus detalhes como cor, cheiro, textura, dentre outros.

Os resultados mostraram que dos dez alunos entrevistados, oito apontaram a experimentação como o tipo de atividade que mais gostam na época de Química. Esse interesse por um ensino mais prático foi notado também em outros momentos da entrevista e durante a observação das aulas. A experimentação permite que o estudante compreenda mais acerca do caráter investigativo das ciências, é uma atividade satisfatória para se instigar um posicionamento crítico do aluno, estimulando o levantamento de hipóteses, a construção e refutação de ideias, estabelecendo suas próprias considerações sobre o fenômeno investigado. (PACHECO, 1997). Esse instrumento de ensino deve estar presente nas aulas de ciências, mas sempre de forma problematizada ao que se refere à natureza da ciência. (SILVA; MACHADO; TUNES, 2015).

\section{RELAÇÃO DA QUÍMICA COM OUTRAS DISCIPLINAS}

No roteiro de entrevista questionamos a docente se o ensino de química, estabelecido na escola Waldorf, procura estabelecer relações com outras disciplinas. Diante dessa questão, a docente afirmou que há essa intenção e que ela acontece o tempo todo, em todas as disciplinas, sendo essa relação um anseio da pedagogia Waldorf. Segue o trecho da fala de Helena:

O tempo todo. Na escola Waldorf não tem uma disciplina que você não estabeleça relações com a outra. Das artes ao português, todas. A interdisciplinaridade que todo mundo acha tão difícil é essencial na Escola Waldorf. Não tem como ela acontecer sem isso, então elas são muito entrelaçadas. Às vezes os alunos falam, professora isso é física ou química? E eu falo e aí? É física, química ou está tudo junto? Será que a biologia não está aqui também?

Durante a observação das aulas, foi possível notar essa relação em diferentes momentos. Por exemplo, quando, ao abordar a temática "açúcares", Helena discute sobre a origem dessa substância há séculos atrás na Índia, sobre os processos industriais que o envolve, a cor mais escura desse alimento e ainda, o processo de cristalização. Neste contexto, a professora retrata ainda as diferentes matérias primas do açúcar no Brasil e na Europa, sobre o efeito do tipo de clima sob a escala de produção do açúcar e a origem do nome Sacarose. Ou ainda, quando ao discutir sobre as proteínas, a docente enfatiza a importância do seu consumo para o nosso organismo, destacando que essas substâncias auxiliam na construção e manutenção dos tecidos e órgãos do nosso organismo, na produção de hormônios, dentre outras funções.

$\mathrm{Na}$ entrevista questionamos aos alunos se os conhecimentos de química estavam relacionados com outros saberes que ele aprendeu e ainda pedimos que ele desse pelo menos um exemplo da relação citada. Dos dez alunos entrevistados, nove afirmaram que eles veem relação entre os conhecimentos da química e outras disciplinas. Um aluno disse "mais ou menos", mas não soube se justificar. A tabela a seguir mostra as disciplinas citadas pelos estudantes e o número de alunos que a citaram, visto que esses sujeitos não apontaram uma única disciplina, a soma total de respostas excede o número de nove alunos respondentes. 
Tabela 1 - Lista de disciplinas que possuem relação com os conhecimentos químicos na percepção dos alunos Waldorf

\begin{tabular}{c|c|c|c|c|c}
\hline Disciplina & Biologia & Matemática & Antropologia & Física & História \\
\hline $\mathbf{N}^{\circ}$ de alunos que citaram & 5 & 5 & 4 & 3 & 2 \\
\hline \multicolumn{6}{c}{ Fonte: As autoras. }
\end{tabular}

Dos nove alunos que viram relação da química com outras disciplinas, sete conseguiram dar um exemplo. Neste momento, optamos por trazer alguns exemplos em torno das disciplinas citadas e o conhecimento químico. André referiu como disciplinas a antropologia, a biologia e a matemática e quando questionado acerca de um exemplo do cotidiano que mostrasse alguma dessas relações ele aponta: "Hum, a planta transformando o gás carbônico em oxigênio, o ser humano respirando também.”

Miguel destaca os saberes da biologia, história e matemática. Como exemplo da relação dessas disciplinas com a química cita:

Tipo na biologia, nós estudamos os grupos alimentares que também estudamos aqui [aula de química]. História, a gente está estudando história e aparece um químico, um físico, alguma coisa assim, que viveu a revolução francesa e aconteceram muitas coisas, e ai ele morreu, tipo tudo está em volta da história. E na matemática a gente trabalha com quantidade, dissolução para misturar, para dar certo.

Para Henrique os saberes da antropologia e da biologia possuem relação com a química, como exemplo, ele cita o processo de fotossíntese. Rafael destaca em outro momento da entrevista a relação entre a química e a física, citando os computadores: "É que aquele negócio dos computadores eu acho que teria relação com física por causa da eletricidade.”

Elisa ao relacionar a biologia com a química destaca:

Sobre a mastigação no início da época que a gente começou a falar do açúcar e da comida também, da digestão, quando ela está na boca e tal, um monte de coisa que a gente recordou.

É interessante observar que os alunos conseguem trazer exemplos próximos do seu cotidiano e que esses, possuem relação entre os saberes das disciplinas apontadas. Na verdade, trata-se de exemplos simples que não foram muito explorados pelas pesquisadoras, no entanto, já permitem constatar que os alunos não veem a química como um conhecimento totalmente isolado dos demais. Isso é um aspecto bem significante visto que no ensino de química tradicional, os estudantes não veem sentido em estudar a química e nem relação desses saberes com os outros que estão estudando, muitas vezes, em um mesmo período de tempo. (CHASSOT, 2007). Vale destacar ainda, que muitas das relações que eles conseguem fazer, remontam conhecimentos estudados em épocas que aconteceram a até dois anos atrás, demonstrando como esta interligação faz dos saberes algo duradouro e significativo, e como tal, não é passageiro ou facilmente esquecido.

Assim, podemos afirmar que a proposta de abordagem dos saberes constituída na escola Waldorf possui grandes potencialidades para a introdução de um ensino que estabeleça relações entre diferentes conhecimentos. Dentro das ciências, esse tipo de abordagem pode contribuir para uma visão mais ampla e integrada dos conhecimentos físicos, químicos, biológicos, dentre outros que abarcam as ciências naturais, aspecto defendido em pesquisas da área de ensino de química. (REIS, 2012; AUTORES APEC, 2003; LIMA; SILVA, 2007).

\section{AVALIAÇÃO}

Ao investigar sobre o ensino de qualquer disciplina, torna-se importante conhecer o processo de avaliação praticado, aspecto essencial na aprendizagem do aluno. Assim, nesta categoria, apresentamos mais detalhes acerca do processo avaliativo aplicado na Paineira Waldorf, trazendo aspectos que refletem sobre os ideais da sua pedagogia. 
Um dos aspectos questionados na entrevista com a professora foi sobre a proposta de avaliação realizada na escola Waldorf. Diante disso, Helena destacou que não há avaliação quantitativa, isso ocorre somente quando o aluno muda de escola e requerem por exigência de outra instituição, valores sobre o rendimento do aluno. Na escola Waldorf prevalece a avaliação qualitativa em uma perspectiva individual. Como destaca a professora entrevistada, o comportamento e a participação do aluno nas aulas, os relatórios produzidos no caderno da época, o compromisso com a disciplina são os aspectos considerados pertinentes para avaliação: "o que eu observo nesse aluno é a responsabilidade, é a participação na aula, o cumprimento das tarefas, a apresentação do caderno.” (Helena).

Como já retratamos em outro momento, o recurso didático utilizado pelo aluno nas aulas é o caderno produzido por eles, o qual contém os relatórios de todas as aulas realizadas durante a época estudada. O caderno constituído de muitas ilustrações, percepções e conclusões do aluno. Para Helena, ele é a principal fonte de avaliação do aprendizado dos alunos. No trecho seguinte, obtido na entrevista, a docente discute porque é tão importante esse recurso para a aprendizagem dos alunos.

O caderno tem um peso muito grande, porque ali estão os relatórios e se o aluno observou e entendeu a aula, e quando eu leio o relatório dele, eu consigo perceber isso ou não. Fazer o relatório é muito bom, pois põe o aluno diante da dúvida e aí no dia seguinte ele pode vir com essa dúvida e sempre tem a chance de falar sobre aquilo de novo. [...] Mas a avaliação individual, ela acontece todo dia, porque a gente sabe qual aluno é mais atento ou não, o que observa mais e o que observa menos.

Na época investigada, percebemos que o relatório de uma aula é sempre lido no dia seguinte por pelos menos quatro estudantes escolhidos pela docente. Isso leva a professora a retomar o assunto, perceber as dificuldades dos estudantes, quais os pontos que foram compreendidos e solucionar as dúvidas que esses sujeitos ainda apresentam. A docente ainda contribui com sugestões para melhorar a redação do relatório dos alunos. Neste ponto, notamos um aspecto importante nesta conduta da professora, pois instiga a participação dos alunos, levando-os a contribuírem com posicionamentos para os relatórios de seus colegas. Há deste modo um compartilhamento de ideias em todas as aulas da época investigada. Um aspecto muito oportuno quando se busca uma avaliação significativa da aprendizagem do aluno.

Ainda a respeito da avaliação, a docente foi questionada se havia "boletim”, ou seja, um documento que fornecesse o rendimento dos alunos aos pais. A professora afirma que existe e detalha sobre esse documento "É um conceito e quando a gente faz o boletim que os pais recebem, ele é muito descritivo e aponta o que esse menino precisa desenvolver”. Novamente, a partir da fala de Helena, tem-se enfatizado a preponderância da avaliação qualitativa nessa pedagogia.

\section{PERSPECTIVAS DE CONTRIBUIÇÕES DA PEDAGOGIA WALDORF PARA O ENSINO DAS CIÊNCIAS/QUIIMICA NO ENSINO FUNDAMENTAL BRASILEIRO}

A Escola Waldorf possui uma pedagogia diferenciada estruturada em uma filosofia bem particular. Entretanto, consideramos que muitos aspectos, principalmente no que tange ao ensino da química dessa instituição, poderiam trazer benefícios se adotadas nas salas de aula brasileiras. Assim, nesse tópico almejamos elencar aspectos presentes na Escola Waldorf que mostram ter potencial para serem adotadas no Ensino das Ciências/Química no Ensino Fundamental nas escolas tradicionais brasileiras.

Como exemplo, citamos a grande ênfase na experimentação. Nesta escola são trabalhados experimentos simples, sendo todos eles possíveis de serem realizadas pelo professor dentro de uma sala de aula padrão. Muitos dos reagentes e utensílios utilizados encontram-se disponíveis em nosso dia a dia, sendo de fácil aquisição, apontando alternativas concretas para o professor das áreas de ciências. Os experimentos acontecem em sala de aula, visto que a instituição não apresenta laboratório, mostrando, portanto, que os experimentos realizados nessa escola podem ser adotados em qualquer outra instituição, mesmo que em ambientes com condições mais precárias. Ademais, a abordagem dos experimentos ocorre com grande participação dos alunos, com observação em detalhes dessas atividades, valorizando a percepção em torno de diferentes sentidos, como o paladar, olfato, audição. Uma opção com grande potencial para uma sala de aula inclusiva. 
Nesse mesmo contexto, a construção de relatórios pelos alunos, é uma proposta na qual vemos grande potencial para a avaliação da aprendizagem desse sujeito. Ao construí-lo, o aluno pode revelar suas percepções, ponderações e dificuldades em torno da aprendizagem na aula. Esse é mais um recurso que consideramos muito produtivo e que percebemos que o aluno tem muito apreço por ele. Feito cotidianamente, o aluno monta o seu caderno de consultas ou a sua apostila, tendo uma valorização maior para as anotações produzidas pelos alunos acerca das aulas. Vale recordar, entretanto, que sempre, no início da aula, o professor dá um retorno sobre o que o aluno construiu em casa.

O currículo das áreas das ciências Waldorf estruturado a partir de eixos temáticos também traz contribuições ricas para a aprendizagem, uma vez que auxilia na construção de um conhecimento mais interdisciplinar e próximo da realidade do aluno. Esta organização curricular temática, como vimos, é algo presente nos PCN e nas discussões em pesquisas sobre o Ensino das Ciências, que, todavia, não é realidade nas escolas. Na instituição Waldorf, é perceptível que esse currículo pode ser adotado e trazer, efetivamente, muitas contribuições para o ensino da química e de outras áreas do conhecimento.

A ação do professor Waldorf também é um aspecto que merece destaque. Esse sujeito tem um grande comprometimento em estabelecer a interdisciplinaridade ao longo de suas aulas. Ele conhece o currículo como um todo, o que permite que ele estabeleça, ao longo de suas discussões, relações de um saber da química, por exemplo, com outros saberes da biologia, física, história, dentre outros. Isso também ocorre, porque novamente, o currículo em temas auxilia nesse processo, visto que as temáticas trabalhadas nas diferentes épocas se cruzam, possuindo pontos em comum. Assim, ressaltamos para a importância de os professores estarem mais familiarizados com o currículo adotado nas escolas, não só o de sua área, mas também de outros saberes, principalmente das ciências. Pois assim, seria mais fácil estabelecer relações do que se vê nas outras disciplinas com a ministrada por aquele docente.

Não podemos ainda deixar de destacar que um ponto significativo nessas escolas, é o tamanho das turmas, que varia em torno de 15 alunos. Reconhecemos a necessidade de as salas de aula apresentarem um número menor de alunos, para que atividades com participação mais ativa sejam adotadas de forma mais efetiva, como a própria experimentação, e ainda, para favorecer uma educação mais inclusiva.

Outros aspectos se mostram significativos, como a valorização da arte, que ocorre praticamente em todas as épocas, mostrando que é possível trabalhar arte e ciências significativamente. Bem como, a ênfase no trabalho em grupo, que ocorre na época de química, na maioria das vezes, durante a realização dos experimentos e nas leituras dos relatórios. Aspectos que são possíveis de serem trabalhados nas escolas.

No geral, enfatizamos a importância de a química ser trabalhada em anos anteriores do Ensino Fundamental, como a Escola Waldorf faz. Para que o aluno consiga construir ao longo dos anos, uma visão da química mais atrelada às ciências e à sociedade, o que facilitaria muito na aprendizagem da química constituída no Ensino Médio. Diante dos documentos oficiais, é notável que diferentes assuntos trabalhados neste período escolar integram os saberes da química, como por exemplo, a fotossíntese, a respiração, a energia, dentre tantos outros assuntos, que, todavia, não são explorados de forma mais pontual, abordando o caráter químico desses processos.

Diante do que discutimos até o momento, torna-se relevante destacar que essas ponderações, não são questões novas para a pesquisa em Educação em Ciências. Muitas discussões neste âmbito se têm feito, todavia, esses aspectos não são realidade nas escolas brasileiras, havendo ainda uma grande lacuna entre o que se discute e propõe nas pesquisas com o que se faz no ambiente escolar. Quando esses aspectos acontecem, são de forma pontual e não diários como se estabelece na Escola Waldorf. Assim, essas discussões se tornam oportunas para mostrar que é possível tornar a prática escolar mais próxima do que se idealiza nos documentos oficiais e não oficiais sobre a educação, contribuindo efetivamente para a formação crítica do aluno.

\section{ALGUMAS CONSIDERAÇÕES}

O presente estudo possibilitou conhecermos um pouco sobre a pedagogia adotada em uma Escola Waldorf, estabelecendo possíveis olhares para o ensino de química estabelecido em uma instituição que segue essa filosofia de ensino. Neste caminho, conseguimos refletir sobre aspectos que tangenciam um 
ensino de ciências e de química que estabeleça mais relações com a vivência do aluno e com saberes de outras disciplinas, favorecendo a formação de uma visão mais ampla e integradora das ciências, bem como mais próxima da realidade e do contexto social.

Diante disso, os resultados apontaram uma escola que adota uma pedagogia de ensino bem característica e diferente das escolas tradicionais brasileiras, no que concerne ao próprio ensino da química. A partir das entrevistas realizadas com o professor e alunos de uma instituição Waldorf, e da observação de uma época completa de química, foi possível conhecer um ensino no qual prevalece a prática experimental, com uma abordagem que favorece a relação entre as demais disciplinas vistas pelos alunos em diferentes épocas, e ainda a relação com a vivência do aluno. Esses aspectos foram evidenciados em vários momentos nas falas dos alunos e da professora e nas anotações produzidas pelos alunos ao longo da época.

São poucos os trabalhos que discutem acerca do ensino de ciências e as propostas de escolas com pedagogias diferenciadas. No Brasil, o número de escolas que seguem pedagogias diferenciadas, como a Pedagogia Waldorf, Pedagogia Montessori, ou ainda inspirados em projetos como da Escola da Ponte, tem crescido cada vez mais, sendo portanto, uma temática importante para promover uma discussão junto a formação inicial dos professores. De forma que os futuros professores conheçam outras realidades educacionais, mesmo que estas ainda sejam poucas quando comparadas ao número de escolas no país.

\section{REFERÊNCIAS}

ALVES, M. J. P. B. Uma experiência Física de um estudo emocional no ensino regular. 2011, Dissertação (Mestrado via Ensino: Artes Visuais) - Faculdade de Belas Artes, Universidade de Lisboa, Lisboa, 2011.

AUTORES APEC. Por um currículo de ciências voltado para as necessidades de nosso tempo. Presença Pedagógica, Belo Horizonte, v. 9, n. 51, p. 42-55, maio/jun. 2003.

BACHEGA, C. A. Pedagogia Waldorf, um olhar diferente à educação. In.: SCIENCULT - SIMPÓSIO CIENTÍfICO-CULTURAL, 4., 2009, Paranaíba. Anais [...] Paranaíba: UEMS, 2009. v. 1, n. 1, p. 360369.

BARDIN, L. Análise de conteúdo. São Paulo: Edições 70, 2011.

BRASIL. Ministério da Educação e do Desporto. Secretaria da Educação Fundamental. Base Nacional Comum Curricular. (2 ${ }^{\mathrm{a}}$ ed.). Brasília: MEC/SEF, 2016.

BRASIL. Ministério da Educação e do Desporto. Secretaria da Educação Fundamental. Parâmetros Curriculares Nacionais: Ciências Naturais. Brasília: MEC/SEF, 1998.

BRASIL. Lei n 9.394, 20 de dezembro de 1996. Lei de Diretrizes e Bases da Educação Nacional. Brasília, 1996. Disponível em: http://www.planalto.gov.br/ccivil_03/leis/19394.htm. Acesso em: 12 jul. 2019.

BOGARIM, M. C. S. P. B. A qualidade da educação infantil no contexto da pedagogia Waldorf: um estudo de caso. 2012, 157 f. il. Dissertação (Mestrado em Educação) - Faculdade de Educação. Universidade de Brasília, Brasília, 2012.

BOGDAN, R. C.; BIKLEN, S. K. Investigação qualitativa em Educação: uma introdução à teoria e aos métodos. Porto: Porto Editorial, 1994.

CHASSOT, A. Alfabetização científica: questões e desafios para a educação. Ijuí: Unijuí, 2007.

GHELMAN, R. Fenomenologia Goetheanística. Material didático produzido em função do curso promovido pelo Núcleo de Estudo, Pesquisa e Pós-Graduação da Associação Micael em parceria com a Unemat, 2006.

GRIMES, K. J.; STEVENS, D. D. Glass, bug, mud. Phi Delta Kappan, v. 90, n. 9, p. 677-680, may 2009. 
LANZ, R. A pedagogia Waldorf: caminho para um ensino mais humano. São Paulo: Antroposófica, 2003.

LIMA, M. E. C. C.; AGUIAR JUNIOR, O. Professores/as de Ciências, a Física e a Química no Ensino Fundamental. In.: ENCONTRO NACIONAL DE PESQUISA EM EDUCAÇÃO EM CIÊNCIAS, 2., 1999, Valinhos. Anais [...] Valinhos: ENPEC, 1999.

LIMA, M. E. C. C.; SILVA, N. S. A Química no Ensino Fundamental: uma proposta em ação. In.: ZANON, L. B.; MALDANER, O. A. (orgs.). Fundamentos e propostas de Química para a Educação Básica no Brasil. Ijuí: Unijuí, 2007. p. 89-107.

MILARÉ, T.; ALVES FILHO, J. P. Ciências no nono ano do Ensino Fundamental: da disciplinaridade à alfabetização científica e tecnológica. Rev. Ensaio, Belo Horizonte, v. 12, n. 2, p. 101-120, maio/ago. 2010.

MORGAN, H. Maximizing student success with differentiated learning. The Clearing House, [s. l.], v. 87, n. 1, p. 34-38, nov. 2013.

PACHECO, D. A experimentação no Ensino de Ciências. Ciência e Ensino, São Paulo, v. 2, n. 2, p. 10, jun. 1997.

PERRENOUD, P. Pedagogia diferenciada: das intenções à ação. Porto Alegre: Artmed, 2000.

PILONI, P. R. A contribuição da pedagogia Waldorf na formação de jovens para os desafios do século XXI: a experiência da Escola Livre Porto Cuiabá. 2008, 106 f. Dissertação (Mestrado em Educação) - Instituto de Educação, Universidade Federal de Mato Grosso, Cuiabá, 2008.

REIS, R. C. Análise da atividade discursiva em uma sala de aula de Ciências: a Química dos ciclos biogeoquímicos no Ensino Fundamental. 2012, 144 f. Dissertação (Mestrado em Química) - Universidade Federal de Juiz de Fora, Juiz de Fora, 2012.

RICHTER, T. Objetivo pedagógico e metas de ensino de uma escola Waldorf. São Paulo: Federação das Escolas Waldorf no Brasil, 2002.

SANTOS, L. Diferenciação pedagógica: um desafio a enfrentar. Noesis, Lisboa, n. 79, p. 52-57, out./ dez. 2009.

SANTOS, E. C. Vivências espaciais e saberes em uma escola Waldorf: um estudo etnomatemático. 2010, 121 f. Dissertação (Mestrado em Educação Matemática) - Instituto de Geociências e Ciências Exatas, Universidade Estadual Paulista Júlio de Mesquita Filho, Rio Claro, 2010.

SANTOS, E. C. Formação de professores no contexto das propostas pedagógicas de Rudolf Steiner (Pedagogia Waldorf), Maria Montessori e experiência da Escola da Ponte. 2015, 252 f. Tese (Doutorado em Educação Matemática) - Instituto de Geociências e Ciências Exatas, Universidade Estadual Paulista Júlio de Mesquita Filho, Rio Claro, 2015.

SENA, R. M. Construindo sentidos sobre o ensino de ciências no contexto da Pedagogia Waldorf. 2013, 239 f. Dissertação (Mestrado em Educação Científica e Tecnológica) - Universidade Federal de Santa Catarina, Florianópolis, 2013.

SILVA, P. R. Um estudo sobre os desafios para a atuação docente na disciplina ciências do sexto ao nono ano do ensino fundamental. 2014, 126 f. Dissertação (Mestrado em Química) - Instituto de Ciências Exatas, Universidade Federal de Juiz de Fora, Juiz de Fora, 2014.

SILVA, R. R.; MACHADO, P. F. L.; TUNES, E. Experimentar sem medo de errar. In.: SANTOS, W. L. P.; MALDANER, O. A. (orgs.). Ensino de Química em foco. Ijuí: Unijuí, 2015. p. 231-262.

STEINER, R. A prática pedagógica: segundo o conhecimento científico-espiritual do homem. São Paulo: Antroposófica, 2013. 